\title{
The Reproductive and Thyroid Hormonal Profile of Khat (Catha edulis) Chewers
}

\author{
Saeed S. Al-Ghamdi \\ Department of Pharmacology and Toxicology, Faculty of Medicine, Umm Al-Qura University, Makkah, KSA. \\ Email: dr.s.s.alghamdi@gmail.com
}

Received June 14 ${ }^{\text {th }}$ 2012; revised July 20 ${ }^{\text {th }}$ 2012; accepted August $18^{\text {th }}, 2012$

\begin{abstract}
The effects of khat on the hormonal levels have been established; however, the effects on human beings are controversial. The aim of our study was to investigate the possible effects of khat on the levels of serum thyroid hormones, testosterone, estradiol (E2), prolactin and cortisol in men. A total of 50 blood samples were collected from healthy males who referred to chew khat for more than 10 years and analyzed for the above hormones. The results were compared to the hormonal levels of 35 non khat chewers. Chewing khat causes significant increases in the testosterone $(\mathrm{P}<0.03)$, prolactin $(\mathrm{P}<0.05)$, E2 $(\mathrm{P}<0.00005)$, FT3 $(\mathrm{P}<0.04)$, and TSH $(\mathrm{P}<0.05)$ levels. No significant differences were found in the serum level of FT4 between the two groups. The level of cortisol were significantly lower $(\mathrm{P}<0.001)$ in the khat chewers group compared to the control group. This study suggests that khat chewing can cause reduction in the cortisol level, which may cause increases of testosterone, prolactin and E2. In addition, chewing khat increases the level of TSH and FT3 serum levels. Therefore, khat may contribute to the relevant disorders caused by abnormal levels of the studied hormones in the people who are chewing khat
\end{abstract}

Keywords: Estradiol (E2); Free Thyroxine (FT4); Free Triiodothyronine (FT3); Thyrotropin Stimulating Hormone (TSH); Prolactin; Testosterone; Cortisol; Khat

\section{Introduction}

Khat [also spelled qat, kat, or ghat] is the name generally used for Catha edulis plant, which is a green large shrub that belongs to Celastraceae family. It grows wild at altitudes of 1500 to $2000 \mathrm{~m}$ above sea level, and usually reaching six to seven meters in height in Middle East, Somalia East Africa (Ethiopia, Kenya) and the southwestern part of the Arabian Peninsula [1]. Khat harvested during dry and sunny season is more potent than that harvested during cool months of the year [2]. It is a high cash income crop and is profitable to the huge number of people involved in its production and marketing including farmers, distributors and merchants.

Previous studies focus on frequency of use but not on amount of khat used. Therefore, data on prevalence of unproblematic versus problematic use, or dependence, are lacking. Study of Ali et al. [3] and Al-Motarreb et al. [4] that was conducted in Yemen has shown that $61 \%$ of subjects were consuming khat on daily basis for more than three hours. Chewing of khat leaves was found to be more common among adult men than women [5], and found to be common among children as well [4]. Khat leaves contain alkaloids, terpenoids, flavonoids, sterols, glycosides, and tannins. The phenylalkylamines and the cathedulins are the major alkaloids. The cathedulins are based on a polyhydroxylated sesquiterpene skeleton and are basically polyesters of euonyminol; 62 different cathedulins have recently been characterized from fresh khat leaves. The khat phenylalkylamines comprise cathinone (s-[-] cathinone), which is the primary constituent of khat as well as two diastereoisomers: cathine (1S, 2S-[+]-norpseudoephedrine or [+] norsendoephedrine) and norephedrine (1R, 2S-[-]-norephedrine), which are the secondary constituents. These compounds are structurally and pharmacologically related to amphetamine and noradrenaline. Cathinone is found mainly in the young leaves and shoots [6-9].

In the gastrointestinal tract, the astringent characteristics of the tannins in khat accounts for periodontal disease, stomatitis, oesophagitis and gastritis [10,11]. Delay in intestinal absorption contributes to some degree to malnutrition. Tannins and norpseudoephdrine contribute to constipation, the most common medical complaint of the khat user [12]. Khat chewing has also been shown to be a risk factor for duodenal ulcers [13]. Another report also described a patient with impaired liver function attributed to khat chewing [14]. A rather unusual adverse effect on the liver of chewing khat was a parasitic infection of the liver by Fasciola hepatica as a contaminant of 
the khat leaves [15].

Habitual administration of khat extracts showed a deranged systemic capacity to handle oxidative radicals and induces cytotoxic effects in cells of liver and kidney [16-20], low birth-weight babies [21,22], and increases blood pressure [23].

The most comprehensive controlled study evaluating the adverse effects of khat-chewing on different health aspects is that by Kennedy et al. [2]. The study was conducted on 371 males and 335 females from the Republic of Yemen. The participants were categorized as nonlight and heavy chewers and then subjected to a standardized medical history and physical examination, involving each organ system of the body. The results showed that gastrointestinal disorders, namely gastritis, constipation and anorexia, were associated significantly with khat-chewing. Emotional problems including insomnia, headaches and emotional instability were also associated significantly with khat use, especially among males. Khat chewers also had a higher prevalence of respiratory problems, namely bronchitis that the author attributed to smoking accompanying khat-chewing rather than to the habit itself. Female chewers had a higher prevalence of urinary problems. Cardiovascular problems and liver diseases, except for histories of jaundice among females, were not associated with khat use.

There are suspected effect of khat on various reproductive health parameters which can lead to diminished sex performance. Khat consumption may lower libido and sexual performance [17]. Another study revealed that the testicles, epididymis and seminal vesicles of rats were smaller than controls [24]. Khat consumption has been found to reduce semen volume, and sperm malformation $[25,26]$. Effects of khat on reproductive and thyroid hormones have been studied [24,27-30]. However, limited studies have been performed to measure the hormonal profile of people chewing khat. The present study was specifically designed to investigate whether the khat consumption has any detectable effects on reproductive and thyroid hormones.

\section{Materials and Methods}

\subsection{Subjects}

This study was carried out in the Department of Pharmacology and Toxicology, Faculty of Medicine, Umm Al-Qura University in association with Hera General Hospital, Makkah. The Study included 50 male khat chewers and 35 controls (healthy volunteers). Subjects were 25 - 45 years old (Table $\mathbf{1}$ ).

\subsection{Blood Sampling}

Blood samples $(5 \mathrm{~mL})$ were collected in heparinized tubes from each subject. The plasma were separated,
Table 1. Background data of khat chewres and control subjects.

\begin{tabular}{ccc}
\hline & Khat chewers & Control \\
\hline No. of subjects & 50 & 35 \\
Age (years) & $35 \pm 2$ & $34 \pm 4$ \\
Weight (kg) & $65 \pm 6$ & $63 \pm 7$ \\
Duration of use (years) & $10 \pm 1$ & 0 \\
\hline
\end{tabular}

frozen quickly, and stored at $-20^{\circ} \mathrm{C}$ until the time of analysis.

\subsection{Hormonal Assay}

Hormonal assays were performed using the reagents, protocol and quality controls provided by World Health Organization Matched Reagent Program (WHO-MRP) and the assays done according to the protocol described by Sufi et al. [31]. Radio Immuno Assay (RIA) described below was carried out on a pair of approximately same numbers of serum specimens from patients and controls. Serum aliquots were analyzed for Estradiol (E2), Free thyroxine (FT4), Free triiodothyronine (FT3), Thyrotropin stimulating hormone (TSH), Prolactin; Testosterone, Cortisol using commercially available kits (DPC, Los Angeles, CA, USA).

Briefly, the plasma samples were thawed and well mixed and $200 \mu \mathrm{L}$ of each sample was mixed with 200 $\mu \mathrm{L}$ of assay buffer (phosphate-buffered saline, containing $1 \%$ gelatin and $0.1 \%$ thiomersal). The hormones were then extracted from the samples for $3 \mathrm{~min}$ using $4 \mathrm{~mL}$ of diethyl ether. The aqueous phase was frozen using dry ice and then organic phase, containing extracted hormone was decanted into $5 \mathrm{~mL}$ tubes. The solvent was evaporated and the hormones reconstituted using $500 \mu \mathrm{L}$ of the assay buffer. The tubes were vortex and left to stand for $10 \mathrm{~min}$, then vortex again. $100 \mu \mathrm{L}$ of the re-dissolved sample extract was then pipette into assay tubes and assayed for the above hormones.

\subsection{Statistical Analysis}

Results are presented as mean \pm SD. The results were analyzed statistically using the Student's $t$-test for unpaired variables to evaluate the significance of differences between the mean values of the two studied groups. Statistical significance was assured when $\mathrm{P}<0.05$.

\section{Results}

The level of E2 in serum in this study was found to be significantly $(\mathrm{P}<0.00003)$ higher in khat chewers than that in normal controls. The mean concentrations of FT3 and TSH were significantly $(\mathrm{P}<0.02)$ higher in khat chewers than in corresponding control groups, whereas 
the levels of FT4 were not significantly different between the khat chewers and the control group. The serum levels of testosterone and prolactin were significantly higher in khat chewers than the control group $(\mathrm{P}<0.03)$. However, the mean level of serum cortisol was significantly $(\mathrm{P}<$ 0.001) lower in khat chewer's serums than that in normal controls (Figure 1).

\section{Discussion}

Previous investigations of the khat effects have spanned various physiological and metabolic effects. However, most of the previous studies were performed on experimental animals. This study focused on effects of khat using a human as model to measure the reproductive and thyroid hormones, due to the believing of people that khat can play a positive role in sexual activity and maintaining cultural identity. Some fathers who are chewing khat are known to give their own children khat leaves to make them more energetic and stimulated believing that khat chewing increases the ability to study better [1]. The real psychological effects of khat consumption include euphoria, hallucinations and feeling of paranoia [32] and physiological effects are lowering libido and sexual performance [24].

In this study, I evaluated the plasma level of testosterone, prolactin, E2, cortisol, TSH, FT3, and FT4 in 50 volunteers of Saudi men who are known to chew khat for more than 10 years. Khat chewers and non-chewers men studied in the present study were judged not to be under

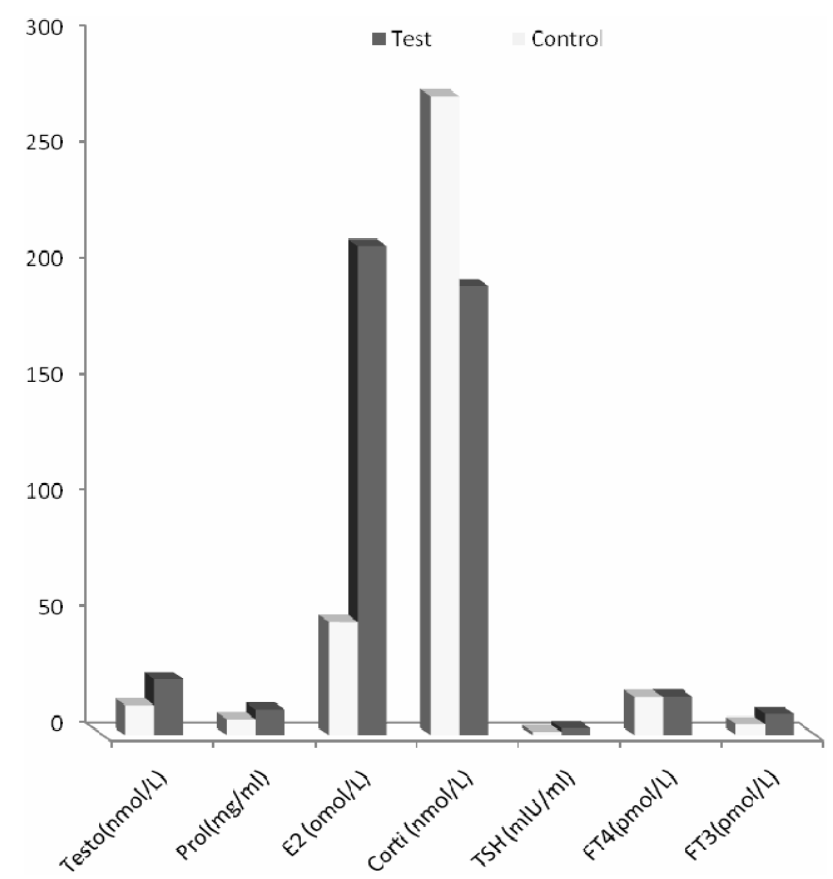

Figure 1. Plasma levels of the FT3, FT4, TSH, prolactine, testosterone, $\mathrm{E} 2$ and cortisol hormones of the khat chewers and the control group. any unusual conditions such as hormone therapy, thyroid and reproductive diseases. I observed an increase in plasma testosterone, prolactin, E2, TSH, and FT3, levels in the khat chewers while the level of plasma cortisol was decreased. However, I did not find any significant difference in the serum level of FT4 between the khat chewers and control groups in the present study. However, it should be noted that even if the plasma levels of the studied hormones are increased or decreased, these changes are still within normal ranges. These findings are in contrast to earlier observations in humans [33], mice [24] and rabbit [34] in which khat consumption resulted in a decrease in plasma testosterone levels, but in agree with Mwenda et al. [27]. Cathinone, which is one of the active ingredients in khat, was responsible for the decrease in testosterone concentration [35]. This could be due to the decrease in cortisol levels. Previous studies by Hall [36] showed that high cortisol cause a reduction in testosterone levels. Thus, the decrease in cortisol levels may have been responsible for the increase of testosterone. Effects of khat on testosterone have been shown to be dose dependent. Albert et al. [34] found that low concentrations of khat extract significantly increased whereas high concentrations suppressed testosterone production, compared to controls.

Increasing in testosterone level however, does not mean that khat may improve the sexual fitness. Previous studies have shown that khat addicts had a reduced semen volume, low sperm count and reduced sperm motility [25,37]. However, limited experiments have also been performed in humans. High level of prolactin in blood stream can also affect male fertility. It has an adverse affect on the function of testicles and can cause decreased testosterone levels or abnormal sperm. This can cause serious problems when it comes time to conceive. Interestingly, prolactin was found to be slightly but significantly elevated in this study in khat chewrs, which is in contrast to earlier observations in the baboon [27], where khat consumption leads to decreasing in the levels of prolactin. high levels of prolactin (hyperprolactinemia) in men leads to gynecomastia, a condition in which the breasts enlarge and look similar to a women. These sign where absent in the subjects of this study. Elevated prolactin levels in men are usually the result of overactive prolactin cells in the pituitary gland. These cells begin to grow into a tumor, called a prolactinoma, on the male pituitary gland and leads to prolactin secretion. No medical history of malignancy was recorded in the studied group; however, induction of prolactinoma by khat cannot be excluded. Such assumption needs to be further investigated.

Testosterone hormone is pharmacologically working as an antagonist to E2, where the high level of one is decreases the level other. In this study, E2 level was 
found to be highly elevated but the level of testosterone remains significantly high as well. The concurrent increase of estradiol levels creates very serious hormonal imbalances such as adiposity, breast development, many cancers, prostate problems, baldness and many other problems commonly associated with advanced age. This result is in agreement with the study of Aziz et al. [38] which was conducted on female rats.

The subjective experience associated with khat-chewing is complex. The effects experienced by chewers can be divided into desirable and non-desirable. The desirable effects are experienced during the first hours of the chewing session. The euphoric state associated with relief from fatigue, energy, feelings of elation and enhanced imagination, and the capability to associate ideas, improved communication ability and high confidence is the primary desirable experiences. Whereas the non-desirable experiences start near its end and continue for some hours, i.e. negative aftermaths $[2,11,33]$. The common adverse effects of khat include insomnia, anorexia, hyperthermia, mydriasis, and endocrineological disturbances $[39,40]$.

Hyperthermia may be explained partially by the thyroid-stimulating effect of khatamines [33]. In this study, FT3 and TSH level were higher in khat chewers. Islam et al. [30] have shown in there experimental study that khat induces $\mathrm{T} 3$ in dose dependent manner. T4 in that study however was induced after high dose of khatamines. In this study, no significant difference in the serum level of FT4 between the khat chewers and control groups were found. However, this might be due to the adapted doses of khat consumed and does not exclude the hypothesis of high dose of khat could increase FT4 level. Vorherr [41] has stated that thyroid hormones may influence metabolism of estrogen. Results of this study suggest that the increase in the serum FT3, and TSH levels, which is coincides with elevation in the serum level of free E2 may be one of the risk factors metabolic disorders.

Discrimination of khat effects on hormonal profiles in previous studies might be attributed to some factors. First, khat chewers have claimed that khat effects are different according to the area of cultivation. They assume that khat cultivated in some areas has stronger effects than others based on this fact. However, this needs to be proven scientifically. Second, using of pesticides by khat famers may contribute to exaggeration effects [42]. Third, effects of smoking habit and genetic polymorphism also should be considered. Tobacco smoking was found to increase the serum levels of various sex hormones including, E2, follicle stimulating hormone, prolactin, testosterone and [43-45].

In conclusion, khat was found to increase the levels of thyroid and reproductive hormones and decreases the level of cortisol. Therefore, it could be a major factor of disorders that caused by such hormonal imbalances. Others factors such as smoking and diet habits, genetic polymorphism, physiological or pathological conditions and chronic medication should not be also neglected.

\section{REFERENCES}

[1] R. A. Manghi, B. B. Riaz Khan, D. Benguettat, Y. Khazaal and D. F. Zullino, "Khat Use: Lifestyle or Addiction?" Journal of Psychoactive Drugs, Vol. 41, No. 1, 2009, pp. 1-10. doi:10.1080/02791072.2009.10400669

[2] J. G. Kennedy, J. Teague and L. Fairbank, "Khat Use in North Yemen and the Problem of Addiction: A Study in Medical Anthropology," Culture, Medicine and Psychiatry, Vol. 4, No. 4, 1980, pp. 311-344. doi:10.1007/BF00051810

[3] A. A. Ali, A. K. Al-Sharabi, J. M. Aguirre and R. Nahas, "A Study of 342 Oral Keratotic White Lesions Induced by Qat Chewing among 2500 Yemeni,” Journal of Oral Pathology and Medicine, Vol. 33, No. 6, 2004, pp. 368372. doi:10.1111/j.1600-0714.2004.00145.x

[4] A. Al-Motarreb, K. Baker and K. J. Broadley, "Khat: Pharmacological and Medical Aspects and Its Social Use in Yemen,” Phytotherapy Research, Vol. 16, No. 5, 2002, pp. 403-413.

[5] I. Dhaifalah and J. Santavy, "Khat Habit and Its Health Effect. A Natural Amphetamine,” Biomedical Papers of the Medical Faculty of the University of Palack, Vol. 148, No. 1, 2004, pp. 11-15.

[6] P. Kelix and O. Braenden, "Pharmacological Aspects of the Chewing of Khat Leaves,” Pharmacological Reviews, Vol. 37, 1985, pp. 149-164.

[7] G. Cox and H. Rampes, "Adverse Effects of Khat: A Review," Advances in Psychiatric Treatment, Vol. 9, 2003, pp. 456-463. doi:10.1192/apt.9.6.456

[8] G. C. Kite, M. Ismail, M. S. Simmonds and P. J. Houghton, "Use of Doubly Protonated Molecules in the Analysis of Cathedulins in Crude Extracts of Khat (Catha edulis) by Liquid Chromatography/Serial Mass Spectrometry," Rapid Communications in Mass Spectrometry, Vol. 17, No. 14, 2003, pp. 1553-1564. doi:10.1002/rcm.1085

[9] Lamina, S. "Khat (Catha edulis); The Herb with OfficioLegal, Socio-Cultural and Economic Uncertainty," South African Journal of Science, Vol. 106, No. 3-4, 2010, pp. 37-43. doi:10.4102/sajs.v106i3/4.155

[10] H. Halbach, "Medical Aspects of the Chewing of Khat Leaves," Bulletin of the World Health Organization, Vol. 47, No. 1, 1972, pp. 21-29.

[11] J. G. Kennedy, J. Teague, W. Rokaw and E. Cooney, “A Medical Evaluation of the Use of Qat in North Yemen," Social Science and Medicine, Vol. 17, No. 12, 1983, pp. 783-793. doi:10.1016/0277-9536(83)90029-1

[12] A. Al-Motarreb, "The Use and Misuse of Khat (Catha edulis) in Changing World: Tradition, Trade and Tragedy," Journal of Ethnopharmacology, Vol. 132, No. 3, 2010, pp. 540-548. doi:10.1016/j.jep.2010.07.001

[13] Y. A. Raja'a, T. A. Noman, T. A. Al-Warafi, A. K. Al- 
Mashraki, N. A. and A. M. Al-Yosofi, "Khat Chewing Is a Risk Factor of Duodenal Ulcer," Saudi Medical Journal, Vol. 21, No. 9, 2000, pp. 887-888.

[14] S. Saha and C. Dollery, "Severe Ischaemic Cardiomyopathy Associated with Khat Chewing," Journal of the Royal Society of Medicine, Vol. 99, No. 6, 2006, pp. 316-318. doi:10.1258/jrsm.99.6.316

[15] A. Cats, P. Scholten, S. G. M. Meuwissen and E. J. Kuipers, "Acute Fasciola Hepatica Infection Attributed to Khat Chewing Khat,” Gut, Vol. 47, No. 4, 2000, pp. 584585. doi:10.1136/gut.47.4.584

[16] A. A. Nasher, A. A. Qirbi, M. A. Ghafoor, A. Catterall, A. Thompson, J. W. Ramsay and I. M. Murray-Lyon, "Khat Chewing and Bladder Neck Dysfunction. A Randomized Controlled Trial of Alpha 1-Adrenergic Blockade," British Journal of Urology, Vol. 75, No. 5, 1995, pp. 597-598. doi:10.1111/j.1464-410X.1995.tb07415.x

[17] N. A. G. M. Hassan, A. A. Gunaid, F. M. Y. El Khally and I. M. Murray-Lyon, “The Subjective Effects of Chewing Qat Leaves in Human Volunteers," Annals of Saudi Medicine, Vol. 22, No. 1-2, 2002, pp. 34-37.

[18] M. Al-Habori, A. Al-Aghbari, A M. l-Mamarym and M. Baker, "Toxicological Evaluation of Catha edulis Leaves: A Long Term Feeding Experiment in Animals,” Journal of Ethnopharmacology, Vol. 83, No. 3, 2002, pp. 209-217. doi:10.1016/S0378-8741(02)00223-4

[19] M. Al-Mamary, M. Al-Habori, A. Al-Aghbari and M. Baker, "Investigation into the Toxicological Effects of Catha edulis Leaves: A Short Term Study in Animals," Phytotherapy Research, Vol. 16, No. 2, 2002, pp. 127132. doi:10.1002/ptr.835

[20] M. Al-Habori, "The Potential Adverse Effects of Habitual Use of Catha edulis (Khat)," Expert Opinion on Drug Safety, Vol. 4, No. 6, 2005, pp. 1145-1154. doi:10.1517/14740338.4.6.1145

[21] N. Abdul Ghani, M. Eriksson, B. Kristiansson and A. Qirbi, "The Influence of Khat-Chewing on Birth-Weight in Full-Term Infants," Social Science and Medicine, Vol. 24, No. 7, 1987, pp. 625-627. doi:10.1016/0277-9536(87)90068-2

[22] M. Eriksson, N. A. Ghani and B. Kristiansson, "KhatChewing during Pregnancy-Effect upon the off-Spring and Some Characteristics of the Chewers," East African Medical Journal, Vol. 68, No. 2, 1991, pp. 106-111.

[23] N. A. Hassan, A. A. Gunaid, A. A. Abdo-Rabbo, Z. Y. Abdel-Kader, M. A. AlMansoob, A. Y. Awad and I. M. Murray-Lyon, "The Effect of Qat Chewing on Blood Pressure and Heart Rate in Healthy Volunteers,” Tropical Doctor, Vol. 30, No. 2, 2000, pp. 107-108.

[24] M. W. Islam, M. Tariq, A. M. Ageel, F. S. El-Feraly, I. A. Al-Meshal and I. Ashraf, "An Evaluation of the Male Reproductive Toxicity of Cathinone,” Toxicology, Vol. 60, No. 3, 1990, pp. 223-234. doi:10.1016/0300-483X(90)90145-7

[25] J. M. Mwenda, M. M. Arimi, M. C. Kyama and D. K. Langat, "Effects of Khat (Catha edulis) Consumption on Reproductive Functions: A Review,” East African Medical Journal, Vol. 80, No. 6, 2003, pp. 318-323.

[26] P. Nencini and A. M. Ahmed, "Khat Consumption: A
Pharmacological Review," Drug and Alcohol Dependence, Vol. 23, No. 1, 1989, pp. 19-29. doi:10.1016/0376-8716(89)90029-X

[27] J. M. Mwenda, R. A. Owuor, C. M. Kyamaa, E. O. Wango, M. M'Arimi and D. K. Langat, "Khat (Catha edulis) up-Regulates Testosterone and Decreases Prolactin and Cortisol Levels in the Baboon,” Journal of Ethnophamacology, Vol. 103, 2006, 2005. pp. 379-384.

[28] A. W. Nyongesa, N. B. Patel, D. W. Onyango, H. O. Odongo and E. O. Wango, "Khat (Catha edulis) Lowers Plasma Luteinizing Hormone (LH) Andtestosterone Secretion, but Increases Cortisol Levels in Male Rabbits,” Journal of Ethnopharmacology, Vol. 116, No. 2, 2008, pp. 245250. doi:10.1016/j.jep.2007.11.022

[29] A. W. Nyongesa, N. B. Patel, D. W. Onyango, H. O. Odongo and E. O. Wango, "In Vitro Study of the Effects of Khat (Catha edulis Forsk) Extract on Isolated Mouse Interstitial Cells,” Journal of Ethnopharmacology, Vol. 110, No. 3, 2007, pp. 401-405. doi:10.1016/j.jep.2006.09.040

[30] M. W. Islam, M. Tariq, F. S. el-Feraly and I. A. al-Meshal, "Effect of Khatamines and Their Enantiomers on Plasma Triiodothyronine and Thyroxine Levels in Normal Wistar Rats,” The American Journal of Chinese Medicine, Vol. 18, No. 1-2, 1990, pp. 71-76. doi:10.1142/S0192415X90000101

[31] S. B. Sufi, A. Donaldson and S. L. Jeffcoate, "World Health Organization Matched Reagent Programme Method Manual," WHO, Geneva, 1996.

[32] R. A. Glennon and D. Showalter, "The Effect of Cathinone and Several Related Derivatives on Locomoter Activity," Research Communications in Substances of Abuse, Vol. 2, 1981, pp. 186-191.

[33] P. Kalix, "Khat: A Plant with Amphetamine Effects," Journal of Substance Abuse Treatment, Vol. 5, No. 3, 1988, pp. 163-169. doi:10.1016/0740-5472(88)90005-0

[34] A. W. Nyongesa, N. B. Patel, D. W. Onyango, E. O. Wango and H. O. Odongo, "In Vitro Study of the Effects of Khat (Catha edulis Forsk) Extract on Isolated Mouse Interstitial Cells," Journal of Ethnopharmacology, Vol. 110, No. 2007, 2006. pp. 401-405.

[35] G. A. Balint, H. Ghebrekidan and E. Balint, "Catha edulis an International Socio-Medical Problem with Considerable Pharmacological Implications,” East African Medical Journal, Vol. 68, No. 7, 1991, pp. 555-561.

[36] P. F. Hall, "Testicular Steroid Synthesis: Organization and Regulation,” In: E. Knobil and J. D. Neill, Eds., Physiology and Reproduction, Raven Press, New York, 1994, pp. 1335-1362.

[37] S. M. El-Shoura, M. Abdel-Aziz, M. E. Ali, M. M. ElSaid, K. Z. Ali, M. A. Keimer, A. M. Raoof, M. Allam and E. M. Elmalik, "Deleterious Effects of Khat Addiction on Semen Parameters and Sperm Ultrastructure," $\mathrm{Hu}$ man Reproduction, Vol. 10, No. 9, 1995, pp. 2295-2300.

[38] H. A. Aziz, K. K. Peh and Y. T. Tan, "Extraction and Microencapsulation of Khat: Effects on Sexual Motivation and Estradiol Level in Female Rats," The Journal of Sexual Medicine, Vol. 6, No. 3, 2009, pp. 682-695. doi:10.1111/j.1743-6109.2008.01157.x 
[39] N. Al-Hebshi and N. Skaug, "Khat (Catha edulis) - An Updated Review,” Addiction Biology, Vol. 10, No. 4, 2005, pp. 299-307. doi:10.1080/13556210500353020

[40] R. Brenneisen, H. V. Fisch, V. Koelbing, S. Gesshusler and P. Kalix, "Amphetamine Like Effect of the Khat Alkaloid Cathinone in Humans," British Journal of Clinical Pharmacology, Vol. 30, No. 6, 1990, pp. 825-828. doi:10.1111/j.1365-2125.1990.tb05447.x

[41] H. Vorherr, "Thyroid Function in Benign and Malignant Breast Disease," European Journal of Cancer and Clinical Oncology, Vol. 23, No. 3, 1987, pp. 255-257. doi:10.1016/0277-5379(87)90066-6

[42] A. Atieq, A. A. Thabet, A. Ghewahi and A. El-Sebae, "Effects of Qat (Catha edulis) Extracts in Combination with Dimethoate on Sperms Quality of Male Mice,” Jour- nal of Environmental Science, Vol. 17, 2009, pp. 31-44.

[43] D. J. Freeman and C. J. Packard, "Smoking and Plasma Lipoprotein Metabolism,” Clinical Science, Vol. 89, 1995, pp. 333-342.

[44] J. Richthoff, S. Alzanaty, L. Rylander, L. Hagmar and A. Gewerman "Association between Tobacco Exposure and Reproductive Parameters in Adolescent Males," International Journal of Andrology, Vol. 31, No. 1, 2008, pp. 3139.

[45] C. H. Ramlau-Hansen, A. M. Thulstrup, A. S. Agerjolm, M. S. Jensen, G. Toft and G. M. Bonde, "Is Smoking a Risk Factor for Decrease Semen Quality? A Cross-Sectional Analysis,” Human Reproduction, Vol. 22, No. 1, 2007, pp. 188-197. doi:10.1093/humrep/del364 